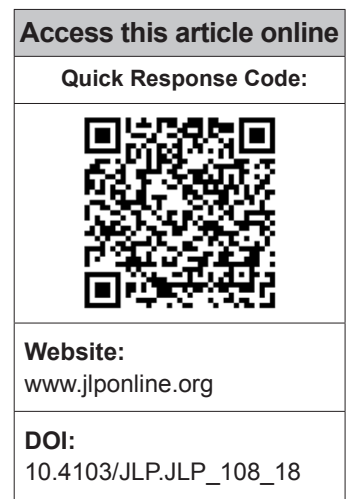

Departments of Laboratory Medicine and ${ }^{2}$ Orthopaedics, Jai Prakash Narayan Apex Trauma Centre, All India Institute of Medical

Sciences, ${ }^{1}$ Department of Microbiology, All India Institute of Medical Sciences, New Delhi, India

Address for correspondence: Dr. Purva Mathur, $2^{\text {nd }}$ Floor, Room No. 212,

Department of Laboratory Medicine, Jai Prakash Narayan Apex Trauma Centre, All India Institute of Medical Sciences, New Delhi, India E-mail: purvamathur@ yahoo.co.in

Submission: 08-08-2018 Accepted: 26-11-2018

\title{
Clostridium sordelli as a cause of gas gangrene in a trauma patient
}

\author{
Vijeta Bajpai, Aishwarya Govindaswamy, Sonu Kumari Agrawal', Rajesh Malhotra², \\ Purva Mathur
}

\section{Abstract:}

Gas gangrene is a necrotic infection of the skin and soft tissue that is associated with high mortality and often necessitating amputation to control the infection. Clostridial myonecrosis is most often cause of gas gangrene and usually present in settings of trauma, surgery, malignancy, and other underlying immunocompromised conditions. The most common causative organism of clostridial myonecrosis is Clostridium perfringens followed by Clostridium septicum. Here, we are reporting an unusual case report of posttraumatic gas gangrene caused by Clostridium sordelli.

Key words:

Clostridium sordelli, matrix-assisted laser desorption/lonization-time-of-flight, myonecrosis, trauma

\section{Introduction}

$C^{l}$ lostridium sordellii is an anaerobic Gram-positive bacillus with subterminal spores and peritrichous flagella. It is commonly not only found in the soil and sewage but also as part of the normal flora of the gastrointestinal tract and vagina of a small percentage of healthy individuals. ${ }^{[1]}$ Although most strains of C. sordellii are nonpathogenic, some virulent, toxin-producing strains cause fatal infections. In contrast, C. sordellii infections are more common in animals. In human's infection, C. sordellii can complicate childbirth, abortion, and gynecological procedures. The prevalence of clostridium myonecrosis, caused by C. sordellii is reported in only $4 \%$ of cases. ${ }^{[2]}$ However, C. sordellii is more commonly reported as a cause of myonecrosis in injection drug abusers and only six sporadic cases of gas gangrene are being reported after trauma. ${ }^{[2]}$ Here, we are reporting an unusual case of gasgangrene in trauma patient cause by C. sordellii.

This is an open access journal, and articles are distributed under the terms of the Creative Commons Attribution-NonCommercial-ShareAlike 4.0 License, which allows others to remix, tweak, and build upon the work non-commercially, as long as appropriate credit is given and the new creations are licensed under the identical terms.

For reprints contact: reprints@medknow.com

\section{Case Report}

A 32-year-old male patient presented to the emergency department of trauma center with a fracture of the right sacroiliac joint along with open wound of right tibial fracture. Elective surgery was performed for sacroiliac disruption and pubic diastasis. Three days after surgery, the patient developed toxic symptoms such as high-grade fever $\left(102^{\circ} \mathrm{F}\right)$, tachycardia, and hypotension. The patient also gave a history of increasing pain out of proportion to physical findings accompanied by progressive swelling, erythema, and crepitus over the right calf leg. The patient was unable to move his right lower extremity and had no sensation below the knee joint level. The physical examination revealed severely swollen and brownish skin of the right lower extremity along with necrotic wound along the fracture site in the calf region. Wound over right calf was also foul smelling. X-ray of the right lower limb revealed gas in the interfacial planes of the leg along with extensive gas formation throughout all the muscle compartments of the right leg. Laboratory evaluation showed increased

How to cite this article: Bajpai V, Govindaswamy A, Agrawal SK, Malhotra R, Mathur P. Clostridium sordelli as a cause of gas gangrene in a trauma patient. J Lab Physicians 2019;11:94-6. 
total leukocyte counts (TLCs) $\left(24,270 / \mathrm{cubic} \mathrm{mm}^{3}\right)$, erythrocyte sedimentation rate, $122 \mathrm{~mm} / \mathrm{h}$, and C-reactive-protein $17.13 \mathrm{mg} / \mathrm{dl}$. In view of the critical condition of the patient, a presumptive diagnosis of gas gangrene was made, and the patient was taken for emergency surgical debridement. Wound was debrided extensively, and pus pockets were removed and washed. Necrosed medial gastrocnemius muscle was debrided completely. Tissue and pus sample was sent to the microbiology laboratory for gram-stain and culture. On gram-staining, variable Gram-positive rods were seen in the smear. The pus and tissue samples were cultured both in the aerobic and anaerobic conditions. After overnight incubation, anaerobic blood agar plate showed growth of transparent and flat colonies with irregular borders. The aerobic culture showed no growth. The colony was taken directly from the primary plate and tested on the automated Matrix Assisted Laser Desorption/Ionization- time-of-flight mass spectrometry system (BioMérieux SA). The organism was identified as $C$. sordelli, with a $99.9 \%$ confidence value. The patient was empirically started injection clindamycin $300 \mathrm{mg}$ intravenously TDS and linezolid 600 $\mathrm{mg}$ intravenously BD. According to culture reports and identification, the patient's antibiotics were deescalated, and he was started injection metronidazole $750 \mathrm{mg}$ OD and injection clindamycin $300 \mathrm{mg}$ intravenously TDS. The patient clinical condition improved after $48 \mathrm{~h}$ of surgical debridement and antibiotic therapy. Once the patient was clinically stable, he received six sittings of hyperbaric oxygen therapy (HOBT). His wound healed well and repeated pus culture from the wound was sterile after 10 days of antibiotic treatment. Patient was completely recovered and was subsequently discharged after 20 days of his hospital stay.

\section{Discussion}

Gas gangrene is a necrotic infection of the skin and soft tissue that is characterized by the presence of gas under the skin, which spreads quickly in soft tissues of the body. ${ }^{[3]}$ Gas gangrene is subclassified into two categories. Most common is traumatic or postoperative gangrene followed by nontraumatic or spontaneous gangrene. C. perfringens is the most common cause of traumatic gas gangrene, isolated in approximately $80 \%$ of cases of gas gangrene, followed by C. septicum, Clostridium novyi, Clostridium histolyticum, Clostridium bifermentans, Clostridium tertium, and Clostridium fallax. ${ }^{[4-6]}$

C. sordellii is an anaerobic, Gram-positive, spore-forming rod, first isolated in 1922 by Argentian microbiologist Alfredo Sordelli. ${ }^{[7]}$ Human infections caused by $C$ sordellii are rarely reported in the literature. Most of the cases of $C$. sordellii infection are reported in healthy young adult women after natural childbirth and spontaneous abortion. Several studies of fatal C. sordellii soft-tissue infection in injection drug users had been reported. ${ }^{[8]}$ The prevalence of $C$. sordellii causing gas gangrene infections are reported in $4 \%$ of patients, globally. ${ }^{[9]}$ While in trauma patients, only six case reports of gas gangrene caused by $C$. sordellii had been published worldwide till date [Table 1]. C. sordelli gas gangrene carries a high mortality in trauma patients as reported in the literature. ${ }^{[10]}$

A presumptive clinical diagnosis of gas gangrene caused by $C$. sordellii can be challenging. Clinical manifestations of C. sordellii infection are insidious in nature and subsequent progressive rapidly. The patient develops excruciating pain with marked local edema; also develop hypotension and tachycardia as described in the present case also. Laboratory tests have demonstrated elevated hematocrit, increased TLC and platelet counts, and decreased serum calcium and protein levels. Specifically, the leukemoid reaction is unique findings in this infection described in various case reports which is highly predictive of fatal outcome. ${ }^{[11,12]}$

The mainstay of treatment is early aggressive surgical intervention, antibiotic therapy, and intensive care support. Wide resection of all necrotic tissues is necessary for better outcome of patient. ${ }^{[13,14]}$ In our case, multiple sittings of debridement and daily dressings, combined with antibiotics and HOBT were the mainstay of treatment which has decreased the clinical severity of the infection and responsible for good prognosis of the patient.

The present case demonstrates that $C$. sordellii should be considered as one of the important causes of gas gangrene in trauma patients. Early recognition and confirmatory diagnosis of unrecognized pathogen like C. sordellii, along with an aggressive surgical approach

\section{Table 1: Summary of Clostridium sordellii infections causing gas gangrene in trauma patients}

\begin{tabular}{llllll}
\hline $\boldsymbol{n}$ & Age year/sex & Presenting illness or condition & Outcome & Year & References \\
\hline 1 & $50 /$ female & Vehicle accident and D2, D3 fracture, leg amputation followed by necrosis & Died & 2010 \\
2 & $38 /$ male & Polytrauma (motorbike fall) cellulitis, myonecrosis & Died & 2008 \\
3 & $4 /$ male & Transverse fracture of the arm & Died & 2006 \\
4 & $37 /$ male & Foot trauma & Survived & 2000 \\
5 & $23 /$ male & Leg trauma & Died & {$[6]$} \\
6 & $42 /$ male & Hand trauma & Survived & 1975 \\
\hline
\end{tabular}


and appropriate antimicrobial therapy, can decrease the mortality among trauma patients.

\section{Acknowledgment}

The authors would like to acknowledge laboratory technicians and staff for laboratory testing of and their support.

\section{Declaration of patient consent}

The authors certify that they have obtained all appropriate patient consent forms. In the form the patient(s) has/ have given his/her/their consent for his/her/their images and other clinical information to be reported in the journal. The patients understand that their names and initials will not be published and due efforts will be made to conceal their identity, but anonymity cannot be guaranteed.

\section{Financial support and sponsorship \\ Nil.}

\section{Conflicts of interest}

There are no conflicts of interest.

\section{References}

1. Cunniffe JG. Clostridium sordellii bacteraemia. J Infect 1996;33:127-9.

2. Kimura AC, Higa JI, Levin RM, Simpson G, Vargas Y, Vugia DJ, et al. Outbreak of necrotizing fasciitis due to Clostridium sordellii among black-tar heroin users. Clin Infect Dis 2004;38:e87-91.
3. Aggelidakis J, Lasithiotakis K, Topalidou A, Koutroumpas J, Kouvidis $\mathrm{G}$, Katonis $\mathrm{P}$, et al. Limb salvage after gas gangrene: A case report and review of the literature. World J Emerg Surg 2011;6:28.

4. Bryant AE, Stevens DL. Clostridial myonecrosis: New insights in pathogenesis and management. Curr Infect Dis Rep 2010;12:383-91.

5. Christie B. Gangrene bug killed 35 heroin users. West J Med 2000;173:82-3.

6. Stevens. Clostridial myonecrosis and other clostridial diseases. In: GoldmanL, Bennett JC, editors. Cecil Textbook of Medicine. $21^{\text {st }}$ ed. Ch. 334. Philadelphia: WB Saunders; 2000. p. 1668-73.

7. Smith LD. Clostridium sordellii, The Pathogenic Anaerobic Bacteria. $2^{\text {nd }}$ ed. Springfield, IL: Charles C. Thomas Publishing; 1975. p. 291-8.

8. Aldape MJ, Bryant AE, Stevens DL. Clostridium sordellii infection: Epidemiology, clinical findings, and current perspectives on diagnosis and treatment. Clin Infect Dis 2006;43:1436-46.

9. Bouvet P, Sautereau J, Le Coustumier A, Mory F, Bouchier C, Popoff MR, et al. Foot infection by Clostridium sordellii: Case report and review of 15 cases in France. J Clin Microbiol 2015;53:1423-7.

10. Browdie DA, Davis JH, Koplewitz MJ, Corday L, Leadbetter AW. Clostridium sordelli infection. J Trauma 1975;15:515-8.

11. Aldape MJ, Bryant AE, Ma Y, Stevens DL. The leukemoid reaction in Clostridium sordellii infection: Neuraminidase induction of promyelocytic cell proliferation. J Infect Dis 2007;195:1838-45.

12. Agrawal P, Garg R. Fulminant leukemoid reaction due to postpartum Clostridium sordellii infection. J Glob Infect Dis 2012;4:209-11.

13. Gredlein CM, Silverman ML, Downey MS. Polymicrobial septic arthritis due to Clostridium species: Case report and review. Clin Infect Dis 2000;30:590-4.

14. Nakagawa M, Sugawa I. Anaerobic cellulitis caused by Clostridium sordellii. Nihon Seikeigeka Gakkai Zasshi 1968;42:69-74. 